\title{
PRODUTIVIDADE, COMPOSIÇÃO MORFOLOGICA E QUÍMICO- BROMATOLÓGICA DO CAPIM-MARANDU CONSORCIADO COM SORGO FORRAGEIRO PARA RENOVAÇÃO DE PASTAGEM DEGRADADA NO CERRADO
}

Andre Roberto Franco Oliveira ${ }^{1}$, Leandro Coelho de Araujo ${ }^{2}$, Mariana Gaioto Ziolkowski Ludkiewicz $^{3}$, Luana Quirino Souza Dayoub Zagato ${ }^{4}$, Fernando Shintate Galindo ${ }^{5}$, Tulio Cesar Maruno 6

\footnotetext{
${ }^{1}$ Mestrando em Zootecnia, Instituto de Zootecnia, Sertãozinho, SP. E-mail: oliveira.8zoo@ gmail.com

${ }^{2}$ Prof. Dr. do Departamento de Biologia e Zootecnia, Universidade Estadual Paulista (UNESP), Faculdade de Engenharia, Câmpus de Ilha Solteira, SP. E-mail: leandroaraujo@bio.feis.unesp.br

${ }^{3}$ Mestranda em Agronomia, Universidade Estadual Paulista (UNESP), Faculdade de Engenharia, Câmpus de Ilha Solteira, SP. E-mail: mariana.gaioto@gmail.com.

${ }^{4}$ Graduanda em Agronomia, Universidade Estadual Paulista (UNESP), Faculdade de Engenharia, Câmpus de Ilha Solteira, SP. E-mail: luana_zagato@yahoo.com.br

${ }^{5}$ Doutorando em Agronomia, Universidade Estadual Paulista (UNESP), Faculdade de Engenharia, Câmpus de Ilha Solteira, SP. E-mail: fs.galindo@ bol.com.br

${ }^{6}$ Graduando em Zootecnia, Universidade Estadual Paulista (UNESP), Faculdade de Engenharia, Câmpus de Ilha Solteira, SP. E-mail: tulioc_maruno@hotmail.com
}

RESUMO: O sistema de integração lavoura pecuária (ILP) tem sido uma forma de renovação de pastagens degradadas, amplamente adotado pelas fazendas comerciais do Cerrado. Além das melhorias na fertilidade e atributos físicos do solo, possibilita aumentos significativos na produção de massa seca para alimentação de bovinos na forma de pastejo. O objetivo deste trabalho foi avaliar o estabelecimento do capim-marandu utilizando o método ILP como alternativa de recuperação de área degradada, avaliando a produtividade total de massa seca, sua composição morfológica e químico-bromatológica após seu estabelecimento. O trabalho foi desenvolvido em Selvíria-MS, em condições de sequeiro, em solo classificado como Latossolo Vermelho-Amarelo distrófico. O delineamento adotado foi em blocos casualizados com cinco repetições. Os tratamentos corresponderam as diferentes formas de renovação da pastagem de capim-decumbens para capim-marandu, utilizando ou não o sorgo forrageiro em consórcio, sendo os tratamentos constituídos de: : (i) método convencional de renovação para capim-marandu solteiro (Marandu); (ii) pastagem degradada de capim-decumbens (Decumbens); capim-marandu semeado simultaneamente com o sorgo e colhidos a (iii) 0,15 (Simultâneo 15) e (iv) 0,45 m (Simultâneo 45) de altura em relação à superfície do solo para silagem; (v) capim-marandu semeado em sucessão ao sorgo solteiro para silagem coletado a $0,45 \mathrm{~m}$ de altura em relação à superfície do solo (Sucessão 45). O tratamento Marandu implantado pelo método convencional apresentou maior produtividade e teor de PB em relação aos demais tratamentos, sendo uma alternativa em curto prazo para renovação de pastagens no Cerrado.

Palavras-chave: Brachiaria brizantha. Estabelecimento de pastagem. Déficit hídrico. 
Sorghum bicolor.

\title{
PRODUCTIVITY, COMPOSITION MORPHOLOGICAL AND CHEMICAL THE GRASS MARANDU INTERCROPPED WITH FORAGE SORGHUM FOR RENEWAL OF DEGRADED PASTURES IN CLOSED
}

\begin{abstract}
The livestock farming system integration (ILP) has been a way of renovation of degraded pastures, widely adopted by commercial farms in the Cerrado. In addition to improvements in fertility and soil physical properties enables significant increases in dry matter production for cattle feed in the form of grazing. The objective of this study was to evaluate the establishment of marandu grass using the ILP method as degraded area recovery alternative, assessing the overall productivity of dry matter, morphological and chemical composition of its establishment. The study was conducted in Selvíria-MS, under rainfed conditions, in a soil classified as Red-Yellow Dystrophic Latosol. The study design was randomized blocks with five replications. The treatments were the different ways of renewing the grass decumbens pasture for marandu grass, with or without the sorghum as a companion crop, and the treatments consisted of: (i) conventional method of renewal for single marandu grass (Marandu ); (ii) degraded pasture grass decumbens (Decumbens); marandu grass seeded concurrently with the picked sorghum and (iii) 0.15 (Simultaneous 15) and (iv) 0,45 m (Simultaneous 45) in height relative to the soil surface for silage; (v) marandu grass sown in succession to single sorghum for silage collected to $0.45 \mathrm{~m}$ in height from the surface soil (Succession 45). The Marandu treatment implemented by the conventional method showed higher productivity and higher crude protein content than the other treatments, being an alternative in the short term to renew pastures in the Cerrado.
\end{abstract}

Key words: Brachiaria brizantha. Pasture establishment. Ddrought. Sorghum bicolor.

\section{INTRODUÇÃO}

O bioma Cerrado é o maior da América do Sul com aproximadamente 204 milhões de ha, o que corresponde a $22 \%$ do território nacional. Segundo Macedo (2009) grande parte dessa área, cerca de 30 milhões de há, é ocupada com pastagem em estádio avançado de degradação.

O sistema ILP tem sido uma forma de renovação de pastagens degradadas, amplamente adotado pelas fazendas comerciais do Cerrado (BALBINO et al., 2011). Além das melhorias na fertilidade e atributos físicos do solo, existem também as possibilidades de aumentos significativos na produção anual de massa seca para alimentação de bovino na forma de pastejo.

A utilização de pastagens, associada à ILP, pode elevar os índices da pecuária, tornando viável a terminação de bovinos durante a entressafra e promovendo melhorias no solo, que beneficiarão o desenvolvimento das culturas de verão (BALBINOT JÚNIOR et al., 2009).

Cultura Agronômica, Ilha Solteira, v.26, n.1, p.69-81, 2017 
Fatos importantes a serem destacados nos últimos anos é a diminuição da área ocupada pela Brachiaria decumbens cv Basilisk em substituição a B. brizantha cv Marandu. A cultivar Marandu ocupa atualmente lugar de destaque na comercialização com cerca de $70 \%$ do volume total das sementes vendidas entre as diversas espécies, inclusive na exportação para a América Latina (MACEDO et al., 2013).

O sorgo tem sido uma opção vantajosa em regiões mais secas onde o milho não propicia uma alta produtividade (OLIVEIRA JÚNIOR et al., 2010; ALBUQUERQUE et al., 2011). Tem se observado que em sistemas de produção de silagem com altura de corte mais elevada, a permanência dos colmos remanescentes na área contribuiu não somente para aumentar a ciclagem da matéria orgânica no solo, mas também para retornar grandes quantidades nutrientes ao solo (COSTA et al., 2014).

O objetivo com esse trabalho foi determinar a produtividade total de massa seca do capim-marandu, sua composição morfológica e química-bromatológica após o seu estabelecimento por diferentes formas de integração com o sorgo forrageiro em um Latossolo Vermelho-Amarelo distrófico no bioma Cerrado.

\section{MATERIAL E MÉTODOS}

O trabalho foi desenvolvido na Fazenda de Ensino Pesquisa e Extensão, da Faculdade de Engenharia de Ilha Solteira Campus da Universidade Estadual Paulista "Júlio de Mesquita Filho" (UNESP), localizada no município de Selvíria-MS, em condições de sequeiro, no Cerrado de baixa altitude $\left(20^{\circ} 22^{\prime} \mathrm{S}\right.$ e $51^{\circ} 22^{\prime} \mathrm{W}$, altitude de $\left.335 \mathrm{~m}\right)$. O solo local foi classificado como Latossolo Vermelho-Amarelo Distrófico (EMBRAPA, 2013), sendo utilizado para pastejo de bovinos a aproximadamente 25 anos, sem qualquer histórico de aplicação de corretivos agrícolas e fertilizantes.

Segundo a classificação de Koppen, o tipo climático da região de estudo é o Aw, tropical úmido com estação chuvosa no verão e seca no inverno e temperatura média anual de $24,5^{\circ} \mathrm{C}$ e precipitação média anual de $1.232 \mathrm{~mm}$. Os dados de temperatura do ar foram registrados diariamente entre o período de 21/11/13 a 22/03/14 por uma estação meteorológica automatizada em Ilha Solteira, SP. A precipitação total durante a condução do experimento foi de $788,9 \mathrm{~mm}$, registrada diariamente por um pluviômetro localizado próximo a área experimental, enquanto que a temperatura e a umidade relativa do ar média foram de $27,3{ }^{\circ} \mathrm{C}$ e $76,2 \%$, respectivamente. Na Figura 1 constam os dados de precipitação pluvial, temperatura mínima, média e máxima registrados durante a condução do experimento. 


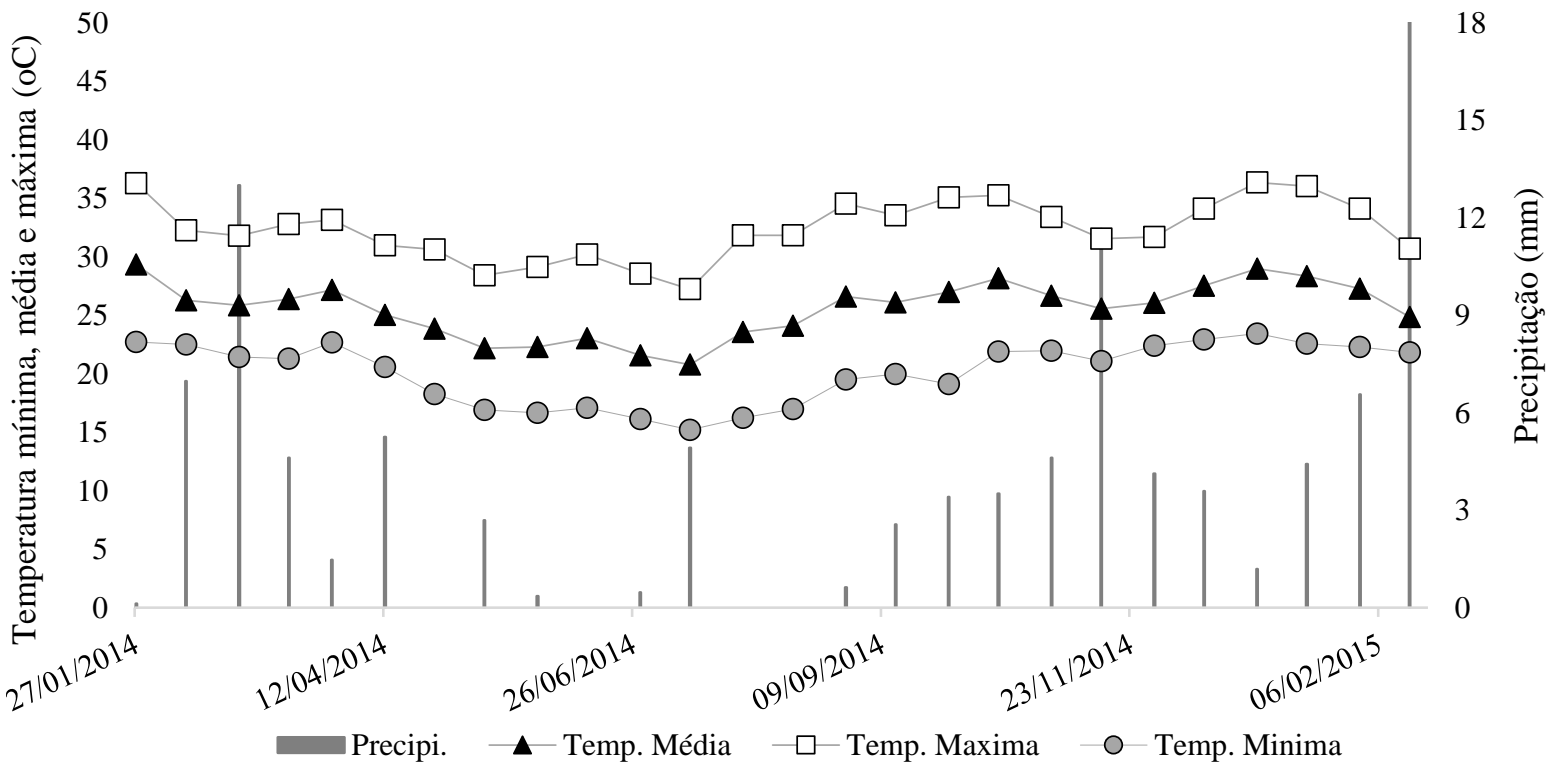

Figura 1. Dados climáticos registrado pela estação meteorológica situada na Fazenda de Ensino, Pesquisa e Extensão/UNESP. Período de Janeiro de 2014 a Fevereiro de 2015.

O delineamento adotado foi em blocos casualizados com cinco repetições. Os tratamentos corresponderam as formas de renovação da pastagem de capim-decumbens para capim-marandu, utilizando ou não o sorgo forrageiro cv. Volumax (Sorghum bicolor (L.) Moench) como cultura acompanhante, sendo os tratamentos constituídos de: (i) método convencional de renovação para capim-marandu solteiro ('Marandu'); (ii) pastagem degradada de capim-decumbens ('Testemunha'); capim-marandu semeado simultaneamente com o sorgo e colhidos a (iii) 0,15 ('Simultâneo 15') e (iv) 0,45 m ('Simultâneo 45') de altura em relação à superfície do solo para silagem; (v) capim-marandu semeado em sucessão ao sorgo solteiro para silagem coletado a $0,45 \mathrm{~m}$ de altura em relação à superfície do solo ('Sucessão 45'), totalizando 25 unidades experimentais com $200 \mathrm{~m}^{2}$ cada.

Foram coletadas amostras compostas, formadas por cinco amostras simples de solo da área total, para determinação e avaliação dos atributos químicos antes da instalação do experimento (27/08/2013) utilizando um trado de caneco. As coletas foram realizadas na profundidade de 0,00 - 0,20 m (caracterização do solo). Após a coleta, as amostras foram secas ao ar, homogeneizadas e posteriormente peneiradas $(2 \mathrm{~mm})$, de forma a se obter a terra fina seca ao ar para seguir com as análises químicas para fins de avaliação da fertilidade do solo conforme descritas em Raij et al. (2001).

Os resultados das análises químicas realizadas antes da instalação do experimento apresentaram valores de $5 \mathrm{mg} \mathrm{dm}^{-3}$ para o P-resina, $3 \mathrm{mg} \mathrm{dm}^{-3}$ para S-SO4, $20 \mathrm{~g} \mathrm{dm}^{-3}$ para matéria orgânica, 4,5 de pH em $\mathrm{CaCl}_{2}, 1 ; 4 ; 6 ; 36 ; 19 ; 11$ e 47 mmolc dm ${ }^{-3}$ para $\mathrm{K}$; Ca; $\mathrm{Mg}$; $\mathrm{H}+\mathrm{Al}$; Al; S.B. e CTC, respectivamente, e $23 \%$ para V. Os teores de micronutrientes corresponderam a 0,$19 ; 2,7 ; 29 ; 10,8$ e $0,1 \mathrm{mg} \mathrm{dm}^{-3}$ para $\mathrm{B}, \mathrm{Cu}, \mathrm{Fe}, \mathrm{Mn}$ e $\mathrm{Zn}$, respectivamente. A análise granulométrica do solo resultou em valores de 248,64 e $689 \mathrm{~g} \mathrm{~kg}^{-1}$ de argila, silte e areia total, respectivamente. Para o estoque de carbono, antes da instalação do experimento,

Cultura Agronômica, Ilha Solteira, v.26, n.1, p.69-81, 2017 
para cada um dos tratamentos ('Testemunha', 'Sucessão 45', 'Simultâneo 15', 'Simultâneo 45' e 'Marandu', respectivamente) foram obtidos os valores de 17,19; 17,42; 17,30; 17,30 e $16,19 \mathrm{Mg} \mathrm{ha}^{-1}$ na camada de $0,00-0,10 \mathrm{~m}$ e 14,$73 ; 16,86 ; 17,25 ; 16,45$ e $14,93 \mathrm{Mg} \mathrm{ha}^{-1}$ na camada de $0,10-0,20 \mathrm{~m}$.

Anteriormente à implantação do experimento, no dia 29/07/2013 foi realizado o procedimento de dessecação da área, com a aplicação em área total de glifosato e carfentrazone-etílica, respectivamente. Com base na análise de solo e com o intuito de elevar a V\% a 60 para o sorgo e $45 \%$ para o capim-marandu solteiro (CFSEMG, 1999), foram distribuídos 2,2 e 1,3 $\mathrm{t} \mathrm{ha}^{-1}$ de calcário dolomítico $(\mathrm{PRNT}=80 \%)$ respectivamente, com parcelamento em duas aplicações para o capim-marandu, nos dias 02/10/13 e 08/10/13, seguido de incorporação com grade. No tratamento 'Testemunha' não foi efetuada a calagem, buscando simular as condições de solo observadas em grande parte das fazendas comerciais no bioma cerrado.

Para o tratamento onde o sorgo foi cultivado solteiro, a semeadura ocorreu em fileiras distanciadas a $0,45 \mathrm{~m}$, objetivando-se um estande final de 130.000 plantas ha $^{-1}$. As sementes foram distribuídas a uma profundidade de $0,02 \mathrm{~m}$, ocorrendo concomitantemente com a adubação (N-P-K+Zn). Nos sistemas de cultivo simultâneo, o capim-marandu foi semeado nas entrelinhas do sorgo $(0,45 \mathrm{~m})$ mantendo-se uma distância de 0,22 $\mathrm{m}$ entre linhas, a uma profundidade de $0,02 \mathrm{~m}$, utilizando-se $7 \mathrm{~kg}$ de sementes puras e viáveis $\mathrm{ha}^{-1}$ no dia 22/11/2013.

Para adubação de semeadura dos tratamentos Simultâneo 15 e 45, foram utilizados 370 $\mathrm{kg}$ da fórmula 8-28-16+Zn conforme CFSEMG (1999), enquanto que para o tratamento 'Marandu' foram utilizados $404 \mathrm{~kg} \mathrm{ha}^{-1}$ da fórmula 8-28-16+Zn (CFSEMG, 1999). A adubação nitrogenada de cobertura foi realizada no dia 14/12/2013, quando as plantas de sorgo apresentavam aproximadamente quatro folhas expandidas, utilizando-se $100 \mathrm{~kg} \mathrm{ha}^{-1} \mathrm{de}$ N para os tratamentos 'Sucessão 45' e 'Simultâneo 15 e 45' adotando-se o V\% para o sorgo; e $80 \mathrm{~kg} \mathrm{ha}^{-1}$ de $\mathrm{N}$ para o tratamento 'Marandu' adotando-se o V\% para o capim, com a fonte ureia.

O sorgo foi colhido visando a produção de silagem no dia 01/04/14, e posteriormente o capim-marandu foi semeado mecanicamente a $0,02 \mathrm{~m}$ de profundidade e em linhas distanciadas à $0,22 \mathrm{~m}$.

As amostras de massa verde de capim-marandu ao final de cada ciclo de rebrotação foram realizadas quando a pastagem apresentou uma interceptação luminosa (IL) aproximada de $95 \%$, estando em torno de $25 \mathrm{~cm}$ de altura para o capim-marandu.

A produtividade da forragem foi estimada pesando individualmente a massa verde coletada em quatro pontos por unidade experimental, delimitadas por uma moldura de 50x50 $\mathrm{cm}$. Os cortes foram realizados na altura de resíduo de $10 \mathrm{~cm}$ e $15 \mathrm{~cm}$ em relação a superfície do solo para os capins decumbens (Decumbens) e marandu (tratamentos Marandu,

Cultura Agronômica, Ilha Solteira, v.26, n.1, p.69-81, 2017 
Simultâneo 15 e 45, e Sucessão 45) respectivamente, estimando a fração de massa disponível para o consumo animal.

Foi retirada uma amostra composta por unidade experimental de $500 \mathrm{~g}$ que foi destinada à separação morfológica em folhas verdes (altura da lígula), colmo verdes (colmo+bainha), material senescente (tecido com mais de $50 \%$ de senescência) e inflorescência, estimando posteriormente o teor de MS em estufa de ventilação forçada a $55^{\circ} \mathrm{C}$ por $72 \mathrm{~h}$.

Os ciclos de avaliações na pastagem tiveram início dia 27/01/14 quando foram realizadas as primeiras avaliações e a última avaliação realizada dia 20/02/15. Na primeira avaliação, o tratamento Marandu apresentava 59 dias após emergência da planta e altura média de $89,6 \pm 6,53 \mathrm{~cm}$, valor superior ao $25 \mathrm{~cm}$ preconizado como ideal para as avaliações. Esta exceção foi considerada exclusivamente para o primeiro corte, visto que o capimmarandu encontrava-se em fase de estabelecimento e caso as avaliações fossem realizadas no início dessa fase $(25 \mathrm{~cm})$ poderia ocorrer desprendimento de plantas do solo e baixo perfilhamento após o pastejo, devido ao sistema radicular ainda apresentar baixo desenvolvimento nesse estágio de desenvolvimento, interferindo diretamente no processo de estabelecimento. Assim, optou-se por um período de estabelecimento de aproximadamente 60 dias após emergência da planta sem a ocorrência de intervenções, procedimento largamente recomendado para propriedades comerciais. Para as demais coletas a altura de corte de $25 \mathrm{~cm}$ foi priorizada.

Concluídas as avaliações previstas para o tratamento Marandu foram inseridos na área onze bovinos para pastejo de 28 a 31/1/14, permanecendo até que o resíduo pós-pastejo de 15 $\mathrm{cm}$ fosse alcançado. Após retirada dos animais, realizou-se as adubações de cobertura com 50 $\mathrm{kg}$ de $\mathrm{N}$ e $\mathrm{K}_{2} \mathrm{O}_{5}$ ha $^{-1}$ na forma de Sulfato de Amônio e KCl, iniciado assim um novo ciclo de rebrotação e avaliações para esse tratamento.

As mesmas avaliações foram conduzidas para o tratamento Decumbens no dia 31/01/14, instante em que a pastagem apresentava altura média de 55,8+5,35 cm. Iniciar as avaliações para ambos os tratamentos em dias próximos teve como finalidade de proporcionar condições climáticas semelhantes para o início do desenvolvimento deles.

No entanto, devido ao atraso no estabelecimento do capim-marandu nos tratamentos consorciados às coletas foram realizadas apenas no dia 23/07/14, com a altura e estabelecimento adequados.

A produtividade de massa seca (PMS) foi estimada coletando todo o material no interior da moldura em cada altura preconizada para os respectivos tratamentos, pesando as massas após a coleta de cada tratamento. Sub amostras dos materiais coletados foram destinadas à estufa. Após esse período o material seco foi pesado e a PMS total estimada por ha. Foram analisadas as médias de produtividade acumulada e média por ciclo de crescimento de massa seca, folha, colmo e material senescente.

Para a determinação da composição bromatológica dos tratamentos foram realizadas análises de PB, FDN, FDA, CZ e Lignina (SILVA; QUEIROZ, 2009).

Cultura Agronômica, Ilha Solteira, v.26, n.1, p.69-81, 2017 
As análises estatísticas foram realizadas com o auxílio do programa SAS (2002) versão 9.0. Para a análise de variância foi utilizado o procedimento de modelos mistos (MIXED) considerando o delineamento em blocos casualizados com cinco repetições. As médias foram ajustadas pelo método dos quadrados mínimos e comparadas ao nível de significância de 5\% de probabilidade pelo teste de Tukey. A medida de dispersão adotada foi o erro-padrão da média.

\section{RESULTADOS E DISCUSSÃO}

As maiores produtividades acumuladas de massa seca total (PMST), folhas (PMSF) e colmo (PMSC), foram observadas no tratamento Marandu com valores de 26.497, 13.932 e $9.748 \mathrm{~kg} \mathrm{ha}^{-1}$, respectivamente, diferindo dos demais tratamentos (Tabela 1). Esse fato ocorreu devido o maior número de ciclos de crescimentos comparado com os demais tratamentos, com valores de 11; 8; 3; 5 e 2 ciclos para Marandu, Decumbens, Simultâneo 15, Simultâneo 45 e Sucessão 45, respectivamente. Este fato indica que o benefício do estabelecimento do capim-marandu pelo método convencional, comparado ao de ILP se limita ao maior número de ciclo no primeiro ano devido ao estabelecimento das pastagens ser antecipado. A contribuição diferenciada dos componentes da pastagem ao longo das estações explica os menores valores de PMS encontrados no período de inverno (tratamentos consorciados), uma vez que a sequência natural da estacionalidade na PMSF e PMSC resulta da influência das estações do ano no ciclo anual de crescimento da gramínea (FAGUNDES et al., 2006). Vale ressaltar que a quantidade de matéria seca produzida, independentemente do tratamento foi considerada satisfatória para garantir a estabilidade do relvado e a produção animal, uma vez que os valores obtidos foram superiores a $1600 \mathrm{~kg} \mathrm{ha}^{-1}$ por corte, o qual é preconizado por Fernandes et al. (2015) como suficiente para garantir o consumo satisfatório de forragem.

Pires (2006) estudando diferentes tipos de Brachiaria, a B. decumbens é a que apresenta menor potencial de PMS, principalmente pelo seu hábito de crescimento decumbente e alta relação caule folha ${ }^{-1}$ ao atingir a maturidade fisiológica, onde no presente estudo a $\mathrm{B}$. decumbens obteve valores para PMS inferiores aos do marandu.

Tabela 1. Produtividade acumulada e média por ciclo de massa seca total (PMST), folha (PMSF), colmo (PMSC) e material senescente (PMSMS) das braquiárias.

\begin{tabular}{ccccc}
\hline Tratamentos & PMST & PMSF & PMSC & PMSMS \\
\cline { 3 - 4 } & \multicolumn{4}{c}{ kg ha $^{-1}$} \\
\hline Marandu & $26.497 \mathrm{a}$ & $13.932 \mathrm{a}$ & $9.748 \mathrm{a}$ & $2.450 \mathrm{a}$ \\
Decumbens & $11.815 \mathrm{~b}$ & $4.397 \mathrm{~b}$ & $4.187 \mathrm{~b}$ & $2.034 \mathrm{a}$ \\
Simultâneo 15 & $7.527 \mathrm{~b}$ & $5.206 \mathrm{~b}$ & $1.454 \mathrm{c}$ & $795 \mathrm{a}$ \\
Simultâneo 45 & $10.025 \mathrm{~b}$ & $7.244 \mathrm{ab}$ & $2.105 \mathrm{c}$ & $632 \mathrm{a}$ \\
Sucessão 45 & $9.852 \mathrm{~b}$ & $5.460 \mathrm{~b}$ & $923 \mathrm{c}$ & $3.469 \mathrm{a}$ \\
\hline \multicolumn{5}{c}{ Média/ciclo } \\
\hline
\end{tabular}

Cultura Agronômica, Ilha Solteira, v.26, n.1, p.69-81, 2017 


\begin{tabular}{ccccc}
\hline Marandu & $2.409 \mathrm{a}$ & $1.267 \mathrm{a}$ & $886 \mathrm{a}$ & $223 \mathrm{a}$ \\
Decumbens & $1.476 \mathrm{a}$ & $550 \mathrm{a}$ & $523 \mathrm{ab}$ & $254 \mathrm{a}$ \\
Simultâneo 15 & $1.505 \mathrm{a}$ & $1.041 \mathrm{a}$ & $291 \mathrm{~b}$ & $159 \mathrm{a}$ \\
Simultâneo 45 & $2.005 \mathrm{a}$ & $1.449 \mathrm{a}$ & $421 \mathrm{ab}$ & $126 \mathrm{a}$ \\
Sucessão 45 & $4.926 \mathrm{a}$ & $2.730 \mathrm{a}$ & $462 \mathrm{ab}$ & $1.735 \mathrm{a}$ \\
\hline
\end{tabular}

Médias seguidas de mesma letra na coluna não diferem pelo teste de Tukey, a 5\% de probabilidade. $\mathrm{N}^{\circ}$ de ciclos: Marandu $=11$, Decumbens $=8$, Simultâneo $15=3$, Simultâneo $45=5$ e Sucessão $45=2$.

O intervalo entre cortes foi de 30 dias, com valor médio de PMS por ciclo para os tratamentos Marandu, Decumbens, Simultâneo 15, 45 e Sucessão 45 de 2.409, 1.476, 1.505, 2.005 e $4.926 \mathrm{~kg} \mathrm{ha}^{-1}$, respectivamente. Quando comparado as variáveis de PMS/ciclo, não foi observada diferença entre os tratamentos, com exceção a PMSC, onde o Marandu diferiu do Simultâneo 15, porém este não diferiu dos demais (Tabela 1).

Resultados obtidos em estudo, são superiores aos $900 \mathrm{~kg} \mathrm{ha}^{-1}$ obtidos por Benett $e t$ al. (2008) em seu primeiro corte avaliado, avaliando o capim-marandu sem adubação. Porém no mesmo estudo realizado pelo autor, no $3^{\circ}$ corte avaliado, os valores de produtividade por ciclo deste estudo foram inferiores aos $4.200 \mathrm{~kg} \mathrm{ha}^{-1}$, exceto no tratamento Sucessão $45(4.926 \mathrm{~kg}$ $\left.\mathrm{ha}^{-1}\right)$.

Viana et al. (2011), avaliando PMS do capim-braquiária (Brachiaria decumbens cv. Basilisk), no período de Janeiro/Fevereiro, obtiveram valor aproximado $\left(1.463 \mathrm{~kg} \mathrm{ha}^{-1}\right)$ ao do presente estudo para o tratamento Decumbens. Santini et al. (2015), obtiveram PMS total em 4 cortes do capim-braquiária próxima de $3.041 \mathrm{~kg} \mathrm{ha}^{-1}$, equivalente a $760 \mathrm{~kg} \mathrm{ha}^{-1}$ por corte, valores estes inferiores aos verificados no presente trabalho.

Segundo Crusciol et al. (2011), a produtividade de matéria seca do capim-marandu consorciado com híbridos de sorgo granífero após a colheita do sorgo em Botucatu-SP, foram de $10.417 \mathrm{~kg} \mathrm{ha}^{-1} \mathrm{de}$ MS. Resultado semelhante ao tratamento Simultâneo 45, com $10.025 \mathrm{~kg}$ $\mathrm{ha}^{-1} \mathrm{de}$ MS, e superior ao tratamento Simultâneo 15 , com valor de $7.527 \mathrm{~kg} \mathrm{ha}^{-1}$. Essa maior produtividade para o tratamento Simultâneo 45 deve-se a maior quantidade de ciclos.

As análises químicas-bromatológica seriam realizadas para os ciclos de crescimento correspondentes ao verão e inverno. No entanto, devido ao atraso no estabelecimento do capim-marandu nos tratamentos consorciados às análises foram realizadas apenas na primeira coleta que ocorreu no dia 23/07/14 onde foram determinadas a matéria mineral, proteína bruta, concentrações de fibra em detergente neutro e ácido, e lignina.

Vale destacar que o déficit hídrico acentuado após a colheita do sorgo (01/04/2014) pode ter contribuído para o baixo desenvolvimento dos tratamentos Simultâneos, onde não foi possível realizar as análises bromatológicas no verão, já o tratamento Sucessão não foi possível realizar nenhuma coleta uma vez que a pastagem não alcançou altura preconizada para o corte no verão e no inverno com o baixo desenvolvimento foi realizado apenas 1 ciclo até a data onde foi realizada as análises. Foi registrado valor acumulado de $69,6 \mathrm{~mm}$ de chuva contra os $675 \mathrm{~mm}$ estimados para evapotranspiração de referência no mesmo período.

Cultura Agronômica, Ilha Solteira, v.26, n.1, p.69-81, 2017 
Para análises bromatológicas, observa-se que no verão os resultados apresentaram valores semelhantes para tratamentos Marandu e Decumbens, com exceção da PB que foi superior para o capim Marandu, com valor de 9,4\%. Esse resultado se justifica pela correção da fertilidade do solo, associado à adubação em cobertura de $\mathrm{N}$ e $\mathrm{K}_{2} \mathrm{O}$ e o correto manejo do pastejo, o que não foi realizado no capim-decumbens (Decumbens). No inverno o tratamento com marandu obteve o maior valor de PB (9,7\%). Os tratamentos Simultâneo 15 e 45 não apresentaram diferenças entre si, com valores de 5,8 e 5,6\%, respectivamente, e o Decumbens apresentou o menor valor de PB (3,3\%) (Tabela 2).

Tabela 2. Teor de proteína bruta (PB), cinzas, fibra em detergentes neutro (FDN) e ácido (FDA) e lignina na massa seca total acima do resíduo conforme os tratamentos e estação do ano.

\begin{tabular}{cccccc}
\hline Tratamento & PB & Cinzas & FDN & FDA & Lignina \\
\hline \multicolumn{5}{c}{ Verão $^{f}$} \\
Darandu & $9,4(0,229)$ a & $4,7(0,384)$ & $63,9(0,632)$ & $33,2(0,762)$ & $1,9(0,311)$ \\
\hline Mecumbens & $7,1(0,229)$ b & $6,7(0,384)$ & $64,5(0,632)$ & $29,9(0,762)$ & $1,1(0,311)$ \\
\hline Marandu & $9,7(0,302)$ a & $5,4(0,228)$ & $62,1(1,55) \mathrm{ab}$ & $30,7(1,17) \mathrm{ab}$ & $1,6(0,187)$ \\
Decumbens & $3,3(0,302)$ c & $5,5(0,197)$ & $67,5(1,55) \mathrm{a}$ & $33,5(1,17) \mathrm{a}$ & $1,8(0,187)$ \\
Simultâneo 15 & $5,8(0,349) \mathrm{b}$ & $5,3(0,197)$ & $55,7(1,55) \mathrm{b}$ & $26,3(1,17) \mathrm{b}$ & $1,4(0,187)$ \\
Simultâneo 45 & $5,6(0,302) \mathrm{b}$ & $5,6(0,228)$ & $59,2(1,55) \mathrm{b}$ & $27,9(1,17) \mathrm{b}$ & $1,4(0,187)$ \\
\hline
\end{tabular}

Médias seguidas de mesma letra na coluna não diferem pelo teste de Tukey, a 5\% de probabilidade. $\mathrm{O}$ erropadrão da média é apresentado entre parênteses. ${ }^{f}$

As análises não foram realizadas para os demais tratamentos, por não apresentarem a altura preconizada para corte nesta estação.

Segundo Van Soest (1994), os teores de proteína bruta das forrageiras inferiores a 7\% ocorrem redução na digestão da mesma devido a inadequados teores de nitrogênio para os microrganismos do rúmen, diminuindo sua população, e consequentemente ocorre redução da digestibilidade e da ingestão da massa seca. Um teor mais alto de PB é necessário para o atendimento das exigências proteicas do organismo animal. Analisando a pastagem da área (Decumbens) seu teor de PB no verão atingiu o mínimo exigido $7,1 \%$, e no inverno se encontra bem inferior, com 3,3\% de PB. Neste caso com a renovação da pastagem com o capim-marandu ocorre o suprimento, já que no Marandu se encontra valores de PB de 9,4 e 9,7\% para verão e inverno, respectivamente.

De acordo com Benett et al. (2008), analisando o efeito de doses de nitrogênio no capim-marandu, o teor de PB obtidos com dose de $50 \mathrm{~kg} \mathrm{ha}^{-1}$ foi de $10,65 \%$, enquanto que neste trabalho foi obtido para o tratamento Marandu teor de PB de 9,4 e 9,7\% no verão e no inverno, respectivamente, um aumento devido a realização da adubação nitrogenada em cobertura após a saída dos animais em cada ciclo. Os valores obtidos para o capim marandu estão abaixo aos obtidos por Teodoro et al. (2012) com valores entre 11,75 e 13,72\%, avaliando diferentes alturas de resíduo.

Cultura Agronômica, Ilha Solteira, v.26, n.1, p.69-81, 2017 
Para os teores de FDN não houve diferença entre os tratamentos. No inverno, o tratamento Decumbens diferiu dos Simultâneo 15 e 45, mas este não diferiu do Marandu (Tabela 2). Tanto no verão, quanto no inverno os valores de FDN, com exceção dos tratamentos Simultâneos no inverno, apresentaram-se acima dos 60\% preconizado como ideal, sendo que valores acima desde influenciam no consumo voluntário dos animais, pois limitam a capacidade ingestiva em virtude do estado de saturação do retículo-rúmen.

Os teores de FDA verificados no presente trabalho foram inferiores aos $40 \%$ tidos como ideal (VAN SOEST, 1994) nas duas estações, sendo que valores acima resultam em decréscimo da digestibilidade. Por conta dos menores teores de FDA e FDN observados nos tratamentos Marandu, Simultâneo 15 e 45 no inverno, haveria aumento no consumo das forragens em ralação ao Decumbens.

Velásquez et al. (2010), avaliando a composição química de forragens tropicais em diferentes idades de corte, obtiveram teores para FDN, FDA e lignina no período de 35 dias para o capim-marandu no verão 51,21; 26,44 e 2,35\% e no inverno de 64,08; 32,89 e 2,95\%, respectivamente. Foram verificados teores de FDN inferiores no verão e superiores no inverno, exceto para o tratamento Decumbens, aos obtidos na presente pesquisa. Teores de FDA verificados pelo autor no verão são inferiores, enquanto no inverno esses teores são superiores aos tratamentos, exceto para o tratamento Decumbens. Já Costa et al. (2014), avaliando Urochloa brizantha cv. Xaraés consorciado ao milho, obteve teores para FDN, FDA e lignina no ano agrícola de 2008/2009 de 60,3, 32,0 e 2,3\%, e no ano agrícola de $2009 / 2010$ de $65,2,34,1$, e 2,5\%, respectivamente. Sendo estes valores compatíveis aos encontrados no presente estudo.

Valores de lignina obtidos na presente pesquisa são inferiores aos observados por Velázques et al. (2010), Pariz et al. (2010) e Costa et al. (2014), com valores que variam de 2,5 a 6,6\%, avaliando quatro espécies de braquiárias semeadas na linha ou a lanço, em consórcio com milho. A lignina tem uma importância para nutrição animal, pois tem uma influência negativa sobre a digestibilidade de outros nutrientes, evidenciada pelas altas correlações negativas do teor de lignina com a digestibilidade da matéria seca, da celulose e da hemicelulose. As fibras em detergente ácido (lignocelulose) são compostas por lignina, celulose e sílica (cinza insolúvel). O aumento nos teores de FDA e lignina gera quedas no coeficiente de digestibilidade (VAN SOEST, 1994).

\section{CONCLUSÃO}

O capim-marandu estabelecido em monocultivo apresentou maior produtividade de massa seca total acumulada e maior concentração de proteína bruta em relação aos demais tratamentos.

O sorgo em sistema de ILP simultâneo pode ser colhido para ensilagem aos 0,15 ou 0,45m de altura em relação a superfície do solo, que não haverá influencia na produtividade de massa seca total acumulada do capim posteriormente. 
O estabelecimento do capim-marandu em sucessão a cultura do sorgo não é uma prática recomendada para as condições em estudo, por ser muito susceptível ao déficit hídrico.

\section{REFERÊNCIAS BIBLIOGRÁFICAS}

ALBUQUERQUE, C. J. B.; VON PINHO, G. V.; RODRIGUES, J. A. S.; BRANT, R. S.; MENDES, M. C. Espaçamento e densidade de semeadura para o sorgo granífero no semiárido. Bragantia, Campinas, v. 70, n. 2, p.278-285, 2011.

BALBINO, L. C.; CORDEIRO, L. A. M.; PORFÍRIO-DA-SILVA, V.; MORAES, A. D.; MARTÍNEZ, G. B.; ALVARENGA, R. C.; KICHEL, A. N.; FONTANELI, R. S.; SANTOS, H. P.; FRANCHINI, J. C.; GALERANI, P. R. Evolução tecnológica e arranjos produtivos de sistemas de integração lavoura-pecuária-floresta no Brasil. Pesquisa Agropecuária Brasileira, Brasília, v. 46, n. 10, p.01-07, 2011.

BALBINOT JUNIOR, A. A.; MORAES, A.; VEIGA, M.; PELISSARI, A.; DIECKOW, J. Integração lavoura-pecuária: intensificação de uso de áreas agrícolas. Ciência Rural, Santa Maria, v. 39, n. 6, p. 1925-1933, 2009.

BENETT, C. G. S.; BUZETTI, S.; SILVA, K. S.; BERGAMASCHINE, A. F.; FABRICIO, J. A. Produtividade e composição bromatológica do capim-marandu a fontes e doses de nitrogênio. Ciência e Agrotecnologia, Lavras, v. 32, n. 5, p.1629-1636, 2008.

COMISSÃO DE FERTILIDADE DO SOLO DO ESTADO DE MINAS GERAIS- CFSEMG. Recomendações para o uso de corretivos e fertilizantes em Minas Gerais. $5^{\text {a }}$ aproximação. Viçosa: UFV, 1999. 359 p.

COSTA, N. R. Desempenho técnico e econômico da produção de milho e sorgo para silagem e soja em sucessão em sistema irrigado de integração lavoura-pecuária no cerrado. 2014. 227 f. Tese (Doutorado em Agronomia) - Faculdade de Engenharia de Ilha Solteira, Universidade Estadual Paulista "Júlio de Mesquita Filho", Ilha Solteira, 2014.

COSTA, N. R.; ANDREOTTI, M.; LOPES, K. S.; DOS SANTOS, F. G.; PARIZ, C. M. Adubação nitrogenada em capins do gênero Urochloa implantados em consórcio com a cultura do milho. Revista Brasileira de Ciências Agrárias, Recife, v. 9, n. 3, p.376-383, 2014.

CRUSCIOL, C. A. C.; MATEUS, G. P.; PARIZ, C. M.; BORGHI, E.; SILVEIRA, J. P. F. Nutrição e produtividade de híbridos de sorgo granífero de ciclo contrastantes consorciados com capim-marandu. Pesquisa Agropecuária Brasileira, Brasília, v. 46, n. 10, p.1234-1240, 2011.

EMPRESA BRASILEIRA DE PESQUISA AGROPECUÁRIA - EMBRAPA. Sistema Brasileiro de Classificação de Solos. Brasília: EMBRAPA, 2013. 353 p.

FAGUNDES, J. L.; FONSECA, D. M. D.; MORAIS, R. V. D.; MISTURA, C.; VITOR, C. M. T.; GOMIDE, J. A.; NASCIMENTO JUNIOR, D.; SANTOS, M. E. R.; LAMBERTUCCI,

Cultura Agronômica, Ilha Solteira, v.26, n.1, p.69-81, 2017 
D. M. Avaliação das características estruturais do capim-braquiária em pastagens adubadas com nitrogênio nas quatro estações do ano. Revista Brasileira de Zootecnia, Viçosa, v. 35, n. 1, p.30-37, 2006.

FERNANDES, J. C.; BUZETTI, S.; DUPAS, E.; TEIXEIRA FILHO, M. C. M.; ANDREOTTI, M. Sources and rates of nitrogen fertilizer used in Mombasa guineagrass in the Brazilian Cerrado region. African Journal of Agricultural Research, Johannesburg, v. 10, n. 19, p.2076-2082, 2015.

MACEDO, M. C. M. Integração lavoura e pecuária: o estado da arte e inovação tecnológicas. Revista Brasileira de Zootecnia, Viçosa, v. 38, supl., p.133-146, 2009.

MACEDO, M. C. M.; ZIMMER, A. H.; KICHEL, A. N.; De ALMEIDA, R. G.; DE ARAÚJO, A. R. Degradação de pastagens, alternativas de recuperação e renovação, e formas de mitigação. In: ENCONTRO DE ADUBAÇÃO DE PASTAGENS DA SCOT CONSULTORIA-TEC-FÉRTIL, 1., 2013, Ribeirão Preto, SP. Anais... Bebedouro: Scot Consultoria, 2013. p. 158-181.

OLIVEIRA JÚNIOR, P. R.; GUALBERTO, R.; OLIVEIRA, P. S. R.; COSTA, N. R.; MONTANS, F. M. Subdoses de herbicida e potássio em cobertura no sistema integração lavoura-pecuária. Pesquisa Agropecuária Tropical, Goiânia, v. 40, n. 3, p.242-250, 2010.

PARIZ, C. M.; FERREIRA, R. L.; SÁ, M. E.; ANDREOTTI, M.; CHIODEROLI, C. A.; RIBEIRO, A. P. Qualidade fisiológica de sementes de Brachiaria e avaliação da produtividade de massa seca, em diferentes sistemas de integração lavoura-pecuária sob irrigação. Pesquisa Agropecuária Tropical, Goiânia, v. 40, n. 3, p.330-340, 2010.

PIRES, W. Manual de pastagem: formação, manejo e recuperação. Viçosa: Aprenda Fácil, 2006. 302 p.

RAIJ, B. van.; ANDRADE, J. C.; CANTARELlA, H.; QUAGGIO, J. A. Análise química para avaliação da fertilidade de solo tropicais. Campinas: IAC, 2001. 285 p.

SANTINI, J. M. K.; BUZETTI, S.; GALINDO, F. S.; DUPAS, E.; COAGUILA, D. N. Técnicas de manejo para recuperação de pastagens degradadas de capim-braquiária (Brachiaria decumbens Stapf cv. Basilisk). Boletim de Indústria Animal, Nova Odessa, v. 72, n. 4, p.331-340, 2015.

SAS INSTITUTE INC. Statistic alanalysis systen user's guide: version 9.0. Cary: Statistical Analysis System Institute, 2002. 513 p.

SILVA, D. J.; QUEIROZ, A.C. Análise de Alimentos: Métodos Químicos e Biológicos. 3. ed. $4^{\mathrm{a}}$ reimpresso. Viçosa: UFV, 2009. 235 p.

TEODORO, M. S. R.; COSTA, K. A. P.; DIAS, F. J. S.; SIMON, G. A.; SAENZ, E. A. C.; SEVERIANO, E. C.; CRUVINEL, W. S. Composição bromatológica dos capins Marandu e Mulato II submetidos a diferentes alturas de resíduo. Global Science and technology, Rio Verde, v. 5, n. 3, p.137-146, 2012.

Cultura Agronômica, Ilha Solteira, v.26, n.1, p.69-81, 2017 
VAN SOEST, P. J. Nutritional ecology of the ruminant. 2. ed. New York: Cornell University, 1994. 476p.

VELÁSQUEZ, P. A. T.; BERCHIELli, T. T.; REIS, R. A.; RIVERA, A. R.; DIAN, P. H. M.; TEIXEIRA, I. A. M. A. Composição química, fracionamento de carboidratos e proteínas e digestibilidade in vitro de forrageiras tropicais em diferentes idades de corte. Revista Brasileira de Zootecnia, Viçosa, v. 39, n. 6, p.1206-1213, 2010.

VIANA, M. C. M.; FREIRE, F. M.; FERREIRA, J. J.; MACÊDO, G. A. R.; CANTARUTTI, R. B.; MASCARENHAS, M. H. T. Adubação nitrogenada na produção e composição química do capim-braquiária sob pastejo rotacionado. Revista Brasileira de Zootecnia, Viçosa, v. 40, n. 7, p.1497-1503, 2011. 